\title{
Predictors for tuberculosis co-infection in people living with HIV/AIDS
}

\author{
Esra Zerdali ${ }^{1}$, İnci Yılmaz Nakir ${ }^{1}$, Serkan Sürme ${ }^{1}$, Uğurcan Sayıl1², Mustafa Yıldırım
}

1. Haseki Education Research Hospital, Infectious Diseases and Clinical Microbiology, İstanbul, Turkey.

2. Karaköprü District Health Directorate, Public Health, Şanlıurfa, Turkey.

\begin{abstract}
Background/aim: Tuberculosis (TB) is one of the most common chronic infectious conditions causing mortality and severe outcomes, particularly in people living with HIV/AIDS (PLWHA). In this study, we aimed to determine the prevalence and predictors of TB among PLWHA.

Materials and methods: We conducted a retrospective and single-center study of adults ( $\geq 18$ years) PLWHA registered at our tertiary teaching and research hospital between 2000 and 2016.

Results: A total of 711 PLWHA were included. Of whom, $633(89.0 \%)$ were male. Mean age was $36.53 \pm 11.55$ years (range, 17-79). Thirty-eight (5.3\%) patients were diagnosed with active TB. TB development was associated with low CD4+ lymphocyte count $(\mathrm{p}<0.001)$, high viral load $(\mathrm{p}=0.040)$ and alcohol consumption $(\mathrm{p}=0.004)$ but no association with age $(p=0.392)$, gender $(p=0.928)$ and duration since anti-retroviral therapy initiation $(p=0.788)$ was found. Also, a receiver operating characteristic analysis showed that the area under the curves of $\mathrm{CD} 4+$ lymphocyte count as a predictor for TB development in PLWHA was 0.717 ( $\mathrm{p}<0.001)$.

Conclusion: There are still clinical challenges to predict TB diagnosis. However, CD4+ lymphocyte count and viral load may be considered as valuable predictors for TB development. Also, community strategies to reduce harmful effect of alcohol use should be developed.

Keywords: Tuberculosis; HIV viral load; CD4 cell counts.

DOI: https://dx.doi.org/10.4314/ahs.v21i3.6

Cite as: Zerdali E, Nakir IY, Sürme S, Saynl U, Ylldrm M. Predictors for tuberculosis co-infection in people living with HIVI AIDS. Afri Health Sci. 2021;21(3): 995-1002. https:/ / dx.doi.org/10.4314/abs.v21i3.6
\end{abstract}

\section{Introduction}

Tuberculosis (TB) is one of the most common chronic infectious conditions causing mortality and severe outcomes, particularly in people living with HIV/AIDS (PLWHA). Additionally, it causes a significant increase in health expenditures due to prolonged hospitalization. Guidelines recommend HIV testing and counseling to all patients with TB. Therefore, patients with TB warrant prompt initiation of antituberculous therapy and HIV testing. In TB patients co-infected with HIV/ AIDS, antiretroviral therapy (ART) is also necessary regardless of CD4+ T lymphocyte count ${ }^{1,2}$.

The decision to initiate treatment for TB is based on patient (age, risk for progression, exposure risk) and public health factors (concern for loss to follow-up,

\section{Corresponding author:}

Serkan Surme,

Haseki Education Research Hospital, Infectious Diseases and Clinical Microbiology.

34098 Istanbul, Turkey.

Phone number: 905558578517

Email: serkansurme@hotmail.com high transmission risk) as well as clinical (life-threatening conditions and typical symptoms), laboratory and radiographic findings. Also, empiric treatment should be initiated immediately even before the test results in patients who have a high possibility of having TB1.

HIV infection is one of the greatest risk factors for the development of TB which is associated with increased HIV replication and enhanced cytokine expression ${ }^{3}$. Therefore, it is important to determine the prevalence and associated risk factors of TB among PLWHA. In this study, we aimed to assess the prevalence and predictors of TB/HIV coexistence.

\section{Materials and methods}

We conducted a retrospective and single-center study of adults ( $\geq 18$ years) PLWHA registered at our tertiary teaching and research hospital between 2000 and 2016. The patients followed up for at least 2 years were included in the study. PLWHA who had no proper follow-up datasheet or missing major data were excluded. The demographic data including age, gender, sexual orientation, and the localization of TB (pulmonary vs. extrapulmonary) and laboratory test results including 
baseline CD4+ T cell count, HIV RNA and tuberculin skin test (TST) were collected and assessed retrospectively from follow-up datasheets.

The diagnosis of TB was made basis on a combination of the following; the history of fever longer than onemonth duration, cough longer than three weeks duration, significant weight loss, contact with an adult with confirmed TB, and presence of acid-fast bacilli (AFB) in sputum/body fluids, abnormal radiological results, positive TST, and nonresponse to conventional antibiotics $^{1}$.

Definite case of TB was defined as a patient with $M y$ cobacterium tuberculosis complex identified from a clinical specimen by culture or polymerase chain reaction. A case of TB was defined as definite case of TB or one in which a clinician has diagnosed TB and has decided to treat the patient with a full course of TB treatment. Pulmonary TB was defined as a case of TB involving the lung parenchyma. Extrapulmonary TB was defined as a case of $\mathrm{TB}$ involving organs other than the lungs. TB pleural effusion, without radiographic abnormalities in the lungs, was also defined as a case of extrapulmonary TB.

The cases were divided into two groups according to TB diagnosis, and comparative analyses were applied. For the evaluation of the TST performed during TB screening, a diameter of 5 or more millimeters in the indurated area was considered positive ${ }^{4}$. Mortality was defined as all-cause mortality during TB treatment. Additionally, all-cause mortality during a 20 -year study period (between 2000-2020) was evaluated. Mortality was recorded via identity numbers of the patients using the National Death Certificate Database (https://obs. saglik.gov.tr).

Frequencies (n) and percentages (\%) were used to present the descriptive characteristics of the data while numerical variables were represented through mean \pm standard deviation (sd) and median. KolmogorovSmirnov test was used for normal distribution analysis. The Mann-Whitney $U$ test and independent-sample t-test were used to compare the two groups in terms of the continuous variables. Categorical data were compared with Chi-Square test or Fisher's Exact test. A p-value $<0.05$ was considered as statistically significant. The analyses were performed using IBM SPSS-22 (Statistical Package for Social Sciences, Chicago, IL, USA).

\section{Results}

A total of 711 PLWHA were included. Of these, 633 $(89.0 \%)$ were male and the mean age was $36.53 \pm 11.55$ years (range, 18-79). The probable route of transmission was heterosexual intercourse in $329(46.3 \%)$ patients and homosexual intercourse in $143(20.1 \%)$ patients. One hundred-ten $(15.5 \%)$ patients described themselves as bisexual. The CD4+ lymphocyte count $<200 /$ $\mathrm{mm}^{3}, 200-350$ and $\geq 350 / \mathrm{mm} 3$ were reported in 184 (25.9\%), 174 patients (24.6\%) and 353 patients (49.6\%), respectively. HIV RNA $<100,000$ and $\geq 100,000$ were reported in 395 patients $(55.6 \%)$ and 316 patients (44.4\%), respectively. Mean CD4+ lymphocyte count at ART initiation was $373.03 \pm 240.55$ cells $/ \mathrm{mm} 3$ (range, $0-1450)$ and mean plasma HIV RNA was $4.88 \pm 1.01$ $\log 10 \mathrm{iu} / \mathrm{mL}$. Mean duration since ART initiation was $7.54 \pm 14.84$ months. We found that candidiasis was the most common AIDS-defining opportunistic infection $(\mathrm{n}=28,3.9 \%)$ followed by, pneumocystis pneumonia $(\mathrm{n}=16,2.3 \%)$, cytomegalovirus infection ( $\mathrm{n}=6,0.8 \%$ ), and cryptococcosis $(\mathrm{n}=1,0.1 \%)$; while Kaposi's sarco$\mathrm{ma}(\mathrm{n}=11,1.6 \%)$ was the most common AIDS-defining malignancy. There were no significant differences between the included $(\mathrm{n}=711)$ and excluded patients $(n=95)$ in terms of age $(p=0.379)$, gender $(p=0.094)$, mean $\mathrm{CD}^{+}$lymphocyte count $(\mathrm{p}=0.431)$ and plasma HIV RNA at ART initiation ( $\mathrm{p}=0.436)$, and duration since ART initiaion $(\mathrm{p}=0.453)$.

Among TB co-infected patients $(\mathrm{n}=38,5.3 \%)$, there were $34(89.5 \%)$ male. The mean age was $37.89 \pm 11.45$ years (range, 17-79). Median duration since ART initiation was 1 (1-82) month. Mean CD4+ lymphocyte count at ART initiation was $218.55 \pm 190.74$ cells $/ \mathrm{mm}^{3}$ (range, 5-839) and mean plasma HIV RNA was $5.11 \pm$ $0.79 \log 10 \mathrm{iu} / \mathrm{mL}$. CD4+ lymphocyte count $<200,200$ 350 and $\geq 350$ cells $/ \mathrm{mm} 3$ were reported in 20 (52.6\%), 11 patients $(28.9 \%)$ and 7 patients $(18.4 \%)$, respectively $(\mathrm{p}<0.001)$. HIV RNA $<100,000$ and $\geq 100,000$ were reported in 15 patients $(3.8 \%)$ and 23 patients $(7.3 \%)$, respectively. All active TB patients were prescribed anti-TB treatment. Mean CD4+ lymphocyte count at ART initiation was $373.03 \pm 240.55$ cells $/ \mathrm{mm} 3$ (range, $0-1450)$ and mean plasma HIV RNA was $4.88 \pm 1.01$ $\log 10 \mathrm{iu} / \mathrm{mL}$. Mean duration since ART initiation was $7.54 \pm 14.84$ months. Of these, 21 (55.3\%) were hospitalized, and two $(5.3 \%)$ died during anti-TB treatment. Unmasking Immune Reconstitution Inflammatory Syndrome (IRIS) was recorded in two patients (5.3\%), while 
paradoxical IRIS was recorded in five patients (13.2\%). Twenty-five patients $(65.7 \%)$ had pulmonary, $11(28.9 \%)$ patients had extrapulmonary and $2(5.3 \%)$ patients had both pulmonary and extrapulmonary TB. Four patients had the disseminated form of TB. The remaining extrapulmonary sites were the lymph nodes $(n=4)$, pleura $(n=3)$, gastrointestinal tract $(n=1)$, and central nervous system $(n=1)$. Table 1 shows the demographic characteristics of PLWHA. We found that candidiasis was the most common AIDS-defining opportunistic infection $(\mathrm{n}=28,3.9 \%)$ followed by, pneumocystis pneumonia $(n=16,2.3 \%)$, cytomegalovirus infection ( $n=6,0.8 \%)$, and cryptococcosis $(n=1,0.1 \%)$; while Kaposi's sarco$\mathrm{ma}(\mathrm{n}=11,1.6 \%)$ was the most common AIDS-defining malignancy. There were no significant differences between the included $(n=711)$ and excluded patients $(\mathrm{n}=95)$ in terms of age $(\mathrm{p}=0.379)$, gender $(\mathrm{p}=0.094)$, mean CD4+ lymphocyte count $(\mathrm{p}=0.431)$ and plasma HIV RNA at ART initiation ( $\mathrm{p}=0.436)$, and duration since ART initiation $(\mathrm{p}=0.453)$

Table 1. The demographic characteristics of people living with HIV/AIDS

\begin{tabular}{|c|c|c|}
\hline & $\mathrm{N}$ & $\%$ \\
\hline Number of patients & 711 & 100 \\
\hline \multicolumn{3}{|l|}{ Age } \\
\hline $18-30$ & 259 & 36.4 \\
\hline $31-40$ & 206 & 29.0 \\
\hline $41-50$ & 153 & 21.5 \\
\hline $51-60$ & 70 & 9.9 \\
\hline$>60$ & 23 & 3.2 \\
\hline \multicolumn{3}{|l|}{ Gender } \\
\hline Male & 633 & 89.0 \\
\hline Female & 78 & 11.0 \\
\hline \multicolumn{3}{|l|}{ Sexual orientation } \\
\hline Heterosexual & 329 & 46.3 \\
\hline Homosexual & 143 & 20.1 \\
\hline Bisexual & 110 & 15.5 \\
\hline NS & 129 & 18.1 \\
\hline \multicolumn{3}{|c|}{ CD4+ count at ART initiation (cells $/ \mathrm{mm}^{3}$ ) } \\
\hline CD4 $(\geq 350)$ & 353 & 49.6 \\
\hline CD4 (200-350) & 174 & 24.6 \\
\hline CD4 $(<200)$ & 184 & 25.9 \\
\hline \multicolumn{3}{|c|}{ HIV RNA level $\log 10$ (iu/mL) at ART initiation } \\
\hline$<100,000$ & 395 & 55.6 \\
\hline$\geq 100,000$ & 316 & 44.4 \\
\hline \multicolumn{3}{|c|}{ Duration since ART initiation } \\
\hline$<3$ months & 451 & 63.4 \\
\hline 3-6 months & 45 & 6.3 \\
\hline$>6$ months & 160 & 22.5 \\
\hline TB co-infected & 38 & 5.3 \\
\hline Pulmonary & 25 & 65.7 \\
\hline Extrapulmonary & 11 & 28.9 \\
\hline Both & 2 & 5.3 \\
\hline \multicolumn{3}{|l|}{ Substance abuse } \\
\hline Smoking & 414 & 58.2 \\
\hline Alcohol & 49 & 6.9 \\
\hline Drug use & 66 & 9.3 \\
\hline Intravenous drug use & 10 & 1.4 \\
\hline \multicolumn{3}{|l|}{ Viral co-infection } \\
\hline Hepatits B & 38 & 5.3 \\
\hline Hepatitis C & 7 & 1.0 \\
\hline
\end{tabular}

Table 2 shows predictors and risk factors for the development of TB co-infection in PLWHA. TB development was not associated with age $(\mathrm{p}=0.392)$, gender $(\mathrm{p}=0.928)$ and duration since ART initiation $(\mathrm{p}=0.788)$. But, TB development was associated with low CD4+ lymphocyte count $(\mathrm{p}<0.001)$ and high viral load $(\mathrm{p}=0.040)$. Additionally, hospitalization was more common in patients with TB co-infection $(\mathrm{p}<0.001)$. Although mortality during a 20 -year study period was more common in patients with TB co-infection, there was no statistically significant difference between the two groups $(p=0.095)$. 
Table 2. Predictors and risk factors for development of tuberculosis co-infection in people living with HIV/AIDS

\begin{tabular}{|c|c|c|c|c|c|c|c|}
\hline & \multicolumn{2}{|c|}{ In total } & \multicolumn{2}{|c|}{ TB co-infected } & \multicolumn{2}{|c|}{$\begin{array}{l}\text { TB non- } \\
\text { infected }\end{array}$} & \\
\hline & \multicolumn{2}{|c|}{ n (\%) } & \multicolumn{2}{|c|}{$n(\%)$} & \multicolumn{2}{|c|}{$n(\%)$} & p value \\
\hline Number of patients & \multicolumn{2}{|c|}{$711(100)$} & \multicolumn{2}{|c|}{$38(5.3)$} & \multicolumn{2}{|c|}{$673(94.7)$} & \\
\hline Age & & & & & & & $0.392 \ddagger$ \\
\hline Mean \pm sd & \multicolumn{2}{|c|}{$36.53 \pm 11.55$} & \multicolumn{2}{|c|}{$37.89 \pm 11.45$} & \multicolumn{2}{|c|}{$36.46 \pm 11.56$} & \\
\hline Median & \multicolumn{2}{|c|}{$34(17-76)$} & \multicolumn{2}{|c|}{$35(19-66)$} & \multicolumn{2}{|c|}{$34(17-76)$} & \\
\hline Gender & & & & & & & $0.928^{*}$ \\
\hline Male & \multicolumn{2}{|c|}{$633(89.0)$} & \multicolumn{2}{|c|}{$34(89.5)$} & \multicolumn{2}{|c|}{$599(89.0)$} & \\
\hline Female & \multicolumn{2}{|c|}{$78(11.0)$} & \multicolumn{2}{|c|}{$4(10.5)$} & \multicolumn{2}{|c|}{$74(11.0)$} & \\
\hline \multicolumn{8}{|c|}{ HIV RNA $\log 10$ at ART initiation (iu/mL) } \\
\hline Mean \pm sd & \multicolumn{2}{|c|}{$4.88 \pm 1.01$} & \multicolumn{2}{|c|}{$5.11 \pm 0.79$} & \multicolumn{2}{|c|}{$4.87 \pm 1.02$} & $0.157 ¥$ \\
\hline Median & \multicolumn{2}{|c|}{$4.83(2.31-8.66)$} & \multicolumn{2}{|c|}{$5.17(3.39-6.60)$} & 4.81 & $31-8.66)$ & \\
\hline$<100,000$ & 395 & 55.6 & 15 & 38.5 & 380 & 56.5 & $0.040^{*}$ \\
\hline$\geq 100,000$ & 316 & 44.4 & 23 & 60.5 & 293 & 43.5 & \\
\hline CD4+ T lymphocyte c & t at $A$ & itiatio & (cell & & & & \\
\hline Mean \pm sd & 373.0 & 0.55 & 218. & 90.74 & 381.7 & 240.23 & $<0.001 \neq$ \\
\hline Median & 350 & & 181. & & 361 & & \\
\hline$\geq 350$ & 353 & 49.6 & 7 & 18.4 & 346 & 51.4 & $<0.001 *$ \\
\hline $200-349$ & 174 & 24.6 & 1 & 28.9 & 163 & 24.2 & \\
\hline $100-199$ & 80 & 11.3 & 8 & 21.1 & 72 & 10.7 & \\
\hline $50-99$ & 43 & 6.0 & 4 & 10.5 & 39 & 5.8 & \\
\hline$<50$ & 61 & 8.6 & 8 & 21.1 & 53 & 7.9 & \\
\hline Duration since ART in & tion ( & hs) & & & & & \\
\hline Mean \pm sd & $7.54 \pm$ & & 10.0 & & $7.39=$ & .58 & $0.831 \neq$ \\
\hline Median & $1(1-$ & & $1(1-$ & & $1(1-$ & & \\
\hline$<3$ months & 451 & 63.4 & 28 & 73.7 & 423 & 62.8 & $0.788^{*}$ \\
\hline 3-6 months & 45 & 6.3 & 2 & 5.3 & 43 & 6.4 & \\
\hline 6 months & 160 & 22.5 & 8 & 21.0 & 152 & 22.6 & \\
\hline Data not available & 55 & 7.7 & 0 & 0 & 55 & 8.2 & \\
\hline Substance abuse & & & & & & & \\
\hline Smoking & 414 & 58.2 & 26 & 68.4 & 388 & 57.6 & $0.190^{*}$ \\
\hline Alcohol & 49 & 6.9 & 7 & 18.4 & 42 & 6.2 & $0.004^{*}$ \\
\hline Drug use & 66 & 9.3 & 5 & 13.2 & 61 & 9.1 & $0.397 *$ \\
\hline Intravenous drug use & 10 & 1.4 & 1 & 2.6 & 9 & 1.3 & $0.425 \dagger$ \\
\hline Hospitalization & 215 & 30.2 & 21 & 55.3 & 194 & 28.8 & $<0.001^{*}$ \\
\hline $\begin{array}{l}\text { Mortality during a 20- } \\
\text { year period }\end{array}$ & 47 & 6.6 & 5 & 13.2 & 42 & 6.2 & $0.095^{*}$ \\
\hline $\begin{array}{l}\text { TB=Tuberculosis ART }=\text { Ant } \\
\text { *: Chi-square was used. } \\
\text { †: Fisher's exact test was use } \\
\text { :: Mann-Whitney U test was } \\
\text { \#. Indenendent sample t-test }\end{array}$ & oviral t & & & & & & \\
\hline
\end{tabular}

TST was recorded in 352 patients (49.5\%). Among patients with TST $\geq 5(\mathrm{n}=108), 56(50.5 \%)$ did not receive TB prophylaxis. However, the remaining patients who did not receive prophylaxis had not developed TB. TB developed in 5 patients who were anergic. These five patients had TB diagnosis after ART initiation. Of the 51 patients without TB, 15 had CD4 $+<200$ cells $/ \mathrm{mm}^{3}$.
A receiver operating characteristic (ROC) analysis showed that the area under the curves (AUC) of CD4+ lymphocyte count as a predictor for TB development in PLWHA were $0.717(\mathrm{p}<0.001)$. To predict TB diagnosis, the cut-off value of CD4+ lymphocyte count was 250 cells $/ \mathrm{mm} 3$, with a sensitivity of $68.42 \%$ and a specificity of $70.57 \%(\mathrm{p}<0.001)$ (Figure). 
Table 3

\begin{tabular}{lll}
\hline CD4+ count Cut-off $\left(\right.$ cells $\left./ \mathbf{m m}^{3}\right)$ & Sensitivity (\%) & Specificity (\%) \\
\hline$\leq \mathbf{5 0}$ & 21.1 & $\mathbf{9 2 . 0}$ \\
$\leq 100$ & 31.6 & 86.2 \\
$\leq 200$ & 52.6 & 75.6 \\
$\leq 250$ & $\mathbf{6 8 . 4}$ & 70.6 \\
$\leq 350$ & 81.6 & 51.3 \\
$\leq \mathbf{5 0 0}$ & 94.7 & $\mathbf{2 6 . 8}$ \\
\hline
\end{tabular}

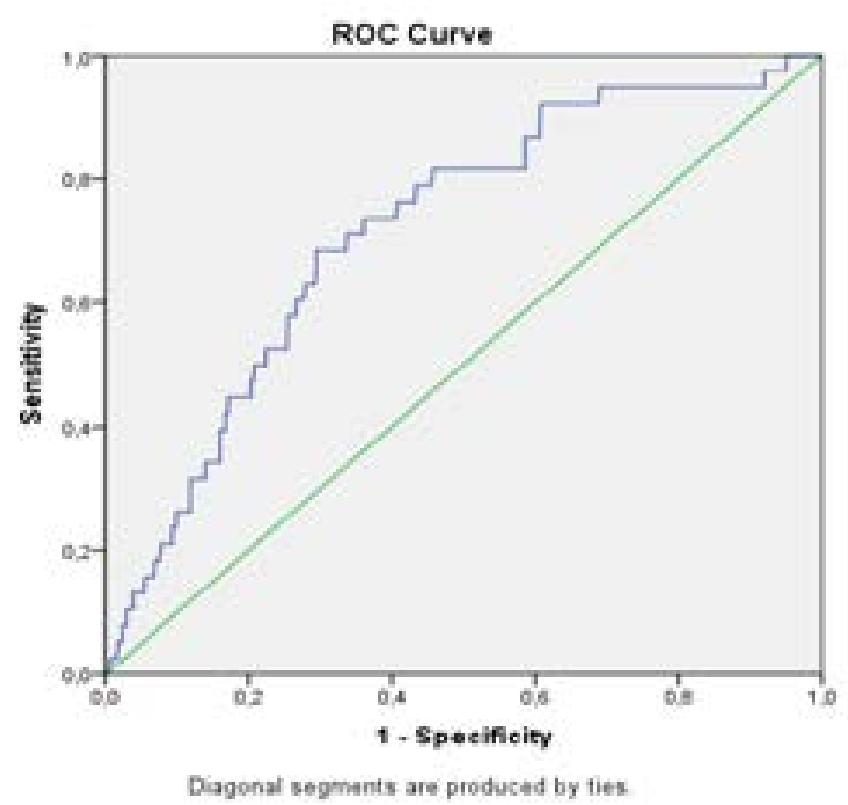

Figure. Receiver operating characteristic curve of $\mathrm{CD}^{+} \mathrm{T}$ lymphocyte count for prediction of TB diagnosis in people living with HIV/AIDS, AUC (\%95 CI) 0.717(0.638-0.796) p<0.001

\section{Discussion}

Our hospital is one of the most important centers in the country because there are many cases. Also, our study population represents nearly $5.5 \%$ of all PLWHA in Turkey. According to the 2019 Global Tuberculosis Report of the World Health Organization (WHO), there were approximately 13,000 (0.016\%) PLWHA and 110 (82-140) TB coinfected patients with PLWHA in Turkey by 2018 (https://www.who.int/tb/publications/ global_report $/$ en $/)^{5}$. However, the data on TB coinfection in Turkey is limited6.

In the present study, the prevalence of TB among PLWHA was $4.5 \%$. According to the WHO, 862,000 out of the 10 million global cases of TB $(8.6 \%)$ were PLWHA. Better healthcare access and early initiation of ART after 2013 might have contributed to our relatively low TB co-infection frequency ${ }^{7-9}$. Also, this may be due to te low prevalence of HIV and low rates of alcohol consumption and substance abuse in Turkey.
In our country, screening HIV among TB patients became mandatory in 2011. And as a consequence of this, the incidence of HIV among TB patients increased 5-fold $(0.1 \%$ vs. $0.5 \%)$ in $2016^{6}$. The Turkish HIV/ AIDS Guideline, which is compatible with international guidelines on strategies to screen and therapies to treat HIV/AIDS, has encouraged initiating ART regardless of CD4+ T lymphocyte count since 2013. Additionally, the Social Security Institution's health benefits package in Turkey is comprehensive. Free screning and treatment for TB and HIV are available for all people. Moreover, all patients are mostly screened before surgical procedures. Also, premarital HIV screening is mandatory. However, Turkey is facing a rising threat: the disclosure of risky practices results in social stigma. The social stigma causes those at risk from coming forward for appropriate stewardship of testing, counseling, and treatment ${ }^{10}$. Thus, anonymous HIV screening programs may be beneficial for people who suffer from social stigma. 
In the present study, TB development was associated with high viral load $(p=0.040)$. In the study of Fenner et al., they showed that viral load was an important predictor for $\mathrm{TB}$, regardless of $\mathrm{CD} 4+$ cell counts7. It may be due to the fact that HIV accelerates the loss of CD4+ T lymphocyte and promotes the progression. In our study, low CD4+ T lymphocyte counts were also associated with a high risk of TB $(p<0.001)$. Of the patients, about a quarter had a CD4+ T lymphocyte count of less than 200 cells $/ \mathrm{mm}^{3}$ and about a half had more than 350 cells $/ \mathrm{mm}^{3}$. This finding was consistent with the study of Gumuser et al. ${ }^{11}$. Also, in the study of Lawn et al., CD4+ cell counts were the dominant predictor of TB development during ART8. HIV infection is associated with deterioration of cellular immune responses and increased risk of opportunistic infections via reduced CD4+ $\mathrm{T}$ lymphocyte count ${ }^{11}$. In the study of Dravid et al., virologic failure on ART was associated with a higher risk for TB development9. Also, recurrence and relapse are associated with low $\mathrm{CD} 4+$ cell counts ${ }^{1}$.

Underlying diseases, immunosuppressive agents, behavioral, social and environmental factors may also play a role as risk factors for $\mathrm{TB}$ development ${ }^{12-16}$. In a recent study, Miyahara et al. demonstrated that the neutrophil to lymphocyte ratio was a predictor of TB among PL$\mathrm{WHA}^{17}$. Substance abuse is one of the most common behavioral risk factor for TB development in PLWHA. In our study, alcohol consumption of more than $40 \mathrm{~g}$ of ethanol per day was associated with increased risk of TB in PLWHA. It was consistent with other studies $^{16,18}$. In contrast, Rao et al. showed that smoking was an independent risk factor, while alcohol consumption was not ${ }^{15}$.

In our study, two patients had gastrointestinal and miliary TB consecutively, the diagnosis was delayed because the symptoms and signs were subtle. One patient developed pulmonary TB while receiving chemotherapy for laryngeal cancer in the duration of 12 years after ART initiation. Two patients had delayed diagnosis of TB lymphadenitis because TB mimicked the acute retroviral syndrome.

According to the 2018 Official Report of Tuberculosis in Turkey, $61.3 \%(\mathrm{n}=7,616)$ of all TB cases have pulmonary involvement, 33.6\% $(n=4,169)$ have extrapulmonary involvement and $5.1 \%(\mathrm{n}=632)$ have both the pulmonary and extrapulmonary involvement6. In our study, $71.0 \%, 23.7 \%$ and $5.3 \%$ of the patients had pul- monary, extrapulmonary and both pulmonary-extrapulmonary TB respectively, consistent with the overall rates from Turkey.

ART restores and trigger the immune response against opportunistic microorganisms, previously unrecognized tuberculosis can appear within weeks or months after ART initiation. Awareness of TB and TB-related IRIS is crucial in PLWHA. Delayed diagnosis of TB and IRIS whether unmasking or paradoxical may be associated with increased mortality and morbidity, thus an intensive screening latent/active TB before ART initiation is vital to decrease the incidence of TB and IRIS ${ }^{1}$. In our study, unmasking and paradoxical IRIS were recorded in two $(5.3 \%)$ and five patients $(13.2 \%)$ respectively but no death occured during TB treatment among these cases. However, due to lack of diagnostic tests and difficulty distinguishing TB-related IRIS from other AIDS-defining opportunistic infections, TB-related IRIS might be underdiagnosed or misdiagnosed ${ }^{19}$ In the study of Bourgarit et al., the rate of TB-related IRIS was $36.8 \%{ }^{20}$. In a systematic review and meta-analysis of 13,103 PLWHA, IRIS developed in $15.7 \%$ of $\mathrm{HIV} / \mathrm{TB}$ co-infected patients ${ }^{21}$. In the study, Müller et al. reported that the mortality rate among patients developing TB-related IRIS was 3.5\% $(\mathrm{n}=11)$.

Mortality among PLWHA and TB is quite high, because of the immunosuppression and opportunistic diseases. A number of studies show that trimethoprim-sulfamethoxazole prophylaxis may be reduce morbidity and mortality in PLWHA with diagnosed $\mathrm{TB}^{22,23}$. Also, the use of ART significantly reduces mortality rates particularly presence of TB and inpatients with advanced HIV disease ${ }^{24}$. In our study, mortality rate during TB treatment was $5.3 \%$. Some studies have been reported in a variety of settings and the range of mortality which may reach up to $40 \% 0^{25-29}$. In the study of Abdullahi et al., 325 of $3163 \mathrm{HIV} / \mathrm{TB}$ co-infected patients (10.3\%) died within 180 days after initiation of TB treatment ${ }^{28}$. Mabunda et al. found that the mortality rate during a 1-year study period was $12.4 \%{ }^{29}$. Gümüşer et al. showed a high mortality rate among their HIV/TB coinfected patients $(n=14,21.2 \%) 9$. However they defined the mortality as all cause mortality during a 20 -year study period. In our study, all cause mortality during a 20 -year study period was $13.2 \%(n=5)$.

This study has some limitations. First, it was conducted in a single-center. Second, as a retrospective evaluation was conducted on patient records with data entry prior to the study, missing data could not be completed in 
some patients. Third, we did not consider underlying comorbid diseases as risk factors and we did not run a multivariate regression analysis. Also, we did not evaluated outcomes, treatment of $\mathrm{TB}$, treatment related adverse events.

This study has also several strengths. First, this study showed a wide data including numerous cases over fifteen years. Second, this study has generalizability because the results are broadly applicable to many different types of people and situations, but still differences in applications of the treatment, prophylaxis and infection control policies between centers may affect the results. In conclusion, HIV and TB co-infection has been a frustrating problem all around the world. There are still clinical challenges to predict TB diagnosis and improve outcomes. However, CD4+ lymphocyte count and viral load may be considered as valuable predictors for TB development in PLWHA. Broadening HIV screening may be the best way to prevent advanced AIDS and curb the TB burden. Also, community strategies to reduce harmful effect of alcohol use should be developed.

\section{Acknowledgement}

The authors declare that they have no competing interests. This research did not receive any specific grant. No funding used. No conflict of interest declared.

The study was conducted in accordance with the Declaration of Helsinki and relevant laws and guidelines, and the study protocol was approved by the local ethics committee (no: 1562, dated 07/12/2018).

\section{Conflict of interest}

None declared.

\section{References}

1. Nahid P, Dorman SE, Alipanah N, Barry PM, Brozek JL, Cattamanchi A, et al. Official American Thoracic Society/Centers for Disease Control and Prevention/ Infectious Diseases Society of America Clinical Practice Guidelines: Treatment of Drug-Susceptible Tuberculosis. Clin Infect Dis. 2016;63:e147-95. https://doi. org/10.1093/cid/ciw376.

2. WHO. Guidelines for treatment of drug-susceptible tuberculosis and patient care. 2017. https://doi. org/10.1586/17476348.1.1.85.

3. Daley CL, Small PM, Schecter GF, Schoolnik GK, McAdam RA, Jacobs WR, et al. An Outbreak of Tuberculosis with Accelerated Progression among Persons Infected with the Human Immunodeficiency Virus. N Engl J Med 1992. https://doi.org/10.1056/ nejm199201233260404.
4. Targeted tuberculin testing and treatment of latent tuberculosis infection. This official statement of the American Thoracic Society was adopted by the ATS Board of Directors, July 1999. This is a Joint Statement of the American Thoracic Society (ATS) and the Centers for Disease Control and Prevention (CDC). This statement was endorsed by the Council of the Infectious Diseases Society of America. (IDSA), September 1999, and the sections of this statement. Am J Respir Crit Care Med. 2000; 161(4 pt 2):S221-47.

5. Global tuberculosis report 2019. World Health Organization. 2019.

6. Ministry of Health. Report on the Battle against Tuberculosis in Turkey. Ankara, Turkey: Ministry of Health; 2018 (in Turkish).

7. Fenner L, Atkinson A, Boulle A, Fox MP, Prozesky H, Zürcher K, et al. HIV viral load as an independent risk factor for tuberculosis in South Africa: Collaborative analysis of cohort studies. J Int AIDS Soc. 2017;20:1-7. https://doi.org/10.7448/IAS.20.1.21327Hasnain M. Cultural approach to HIV/AIDS harm reduction in Muslim countries. Harm Reduct J 2005;2:1-8 PubMed . https://doi.org/10.1186/1477-7517-2-23.

8. Lawn SD, Myer L, Edwards D, Bekker LG, Wood R. Short-term and long-term risk of tuberculosis associated with CD4 cell recovery during antiretroviral therapy in South Africa. AIDS. 2009;23:1717-25. https://doi. org/10.1097/QAD.0b013e32832d3b6d.

9. Dravid A, Natarajan K, Medisetty M, Gawali R, Mahajan U, Kulkarni M, et al. Incidence of tuberculosis among HIV infected individuals on long term antiretroviral therapy in private healthcare sector in Pune, Western India. BMC Infect Dis. 2019;19:1-12. https://doi. org/10.1186/s12879-019-4361-0.

10. Hasnain M. Cultural approach to HIV/AIDS harm reduction in Muslim countries. Harm Reduct J 2005;2:18. https://doi.org/10.1186/1477-7517-2-23.

11. Gümüşer F, Altinkaynak M, Yildiz Sevgi D, Altuntaş Aydin Ö, Mete B, Gündüz A, et al. Human immunodeficiency virus and tuberculosis coinfection: Clinical features and predictors of mortality. Turkish J Med Sci. 2018;48:503-8. https://doi.org/10.3906/sag-1706-76.

12. Baker MA, Lin HH, Chang HY, Murray MB. The risk of tuberculosis disease among persons with diabetes mellitus: a prospective cohort study. Clin Infect Dis. 2012;54(6):818-825. PubMed. doi:10.1093/cid/cir939. 13. Li SY, Chen TJ, Chung KW, et al. Mycobacterium tuberculosis infection of end-stage renal disease patients in Taiwan: a nationwide longitudinal study. Clin Microbiol Infect. 2011;17(11):1646-1652. doi:10.1111/ j.1469-0691.2011.03473.x. 
14. Jick SS, Lieberman ES, Rahman MU, Choi HK. Glucocorticoid use, other associated factors, and the risk of tuberculosis. Arthritis Rheum. 2006;55(1):19-26. PubMed. doi:10.1002/art.21705.

15. Rao VG, Bhat J, Yadav R, et al. Tobacco smoking: a major risk factor for pulmonary tuberculosis--evidence from a cross-sectional study in central India. Trans $R$ Soc Trop Med Hyg. 2014;108(8):474-481. doi:10.1093/ trstmh/tru082

16. Amoakwa K, Martinson NA, Moulton LH, Barnes GL, Msandiwa R, Chaisson RE. Risk factors for developing active tuberculosis after the treatment of latent tuberculosis in adults infected with human immunodeficiency virus. Open Forum Infect Dis. 2015;2(1):ofu120. Published 2015 Jan 20. doi:10.1093/ofid/ofu120.

17. Miyahara R, Piyaworawong S, Naranbhai V, et al. Predicting the risk of pulmonary tuberculosis based on the neutrophil-to-lymphocyte ratio at TB screening in HIV-infected individuals. BMC Infect Dis. 2019;19(1):667. Published 2019 Jul 29. doi:10.1186/s12879-019-4292-9. 18. Lönnroth K, Williams BG, Stadlin S, Jaramillo E, Dye C. Alcohol use as a risk factor for tuberculosis - a systematic review. BMC Public Health. 2008;8:289. Published 2008 Aug 14. doi:10.1186/1471-2458-8-289.

19. Chelkeba L, Fekadu G, Tesfaye G, Belayneh F, Melaku T, Mekonnen Z. Effects of time of initiation of antiretroviral therapy in the treatment of patients with HIV/TB co-infection: A systemic review and meta-analysis. Ann Med Surg (Lond). 2020;55:148-158. Published 2020 May 16. doi:10.1016/j.amsu.2020.05.004.

20. Bourgarit A, Carcelain G, Martinez V, et al. Explosion of tuberculin-specific Th1-responses induces immune restoration syndrome in tuberculosis and HIV co-infected patients. AIDS. 2006;20(2):F1-F7. doi:10.1097/01.aids.0000202648.18526.bf

21. Müller M, Wandel S, Colebunders R, et al. Immune reconstitution inflammatory syndrome in patients starting antiretroviral therapy for HIV infection: a systematic review and meta-analysis. Lancet Infect Dis. 2010;10(4):251261. doi:10.1016/S1473-3099(10)70026-8
22. Nunn AJ, Mwaba P, Chintu C, Mwinga A, Darbyshire JH, Zumla A. Role of co-trimoxazole prophylaxis in reducing mortality in HIV infected adults being treated for tuberculosis: Randomised clinical trial. BMJ. 2008;337:220-3. https://doi.org/10.1136/bmj.a257.

23. Ku SWW, Jiamsakul A, Joshi K, Pasayan MKU, Widhani A, Chaiwarith R, et al. Cotrimoxazole prophylaxis decreases tuberculosis risk among Asian patients with HIV. J Int AIDS Soc. 2019;22:1-10. https://doi. org/10.1002/jia2.25264.

24. Garcia-Vidal C, Salvado M, Salavert M. Timing of antiretroviral drugs during tuberculosis therapy. $N$ Engl J Med 2010;362:2137-8. https://doi.org/10.1056/NEJMc1003767.

25. Castro SS, Scatena LM, Miranzi A, Miranzi Neto A, Nunes AA. Characteristics of cases of tuberculosis coinfected with HIV in Minas Gerais State in 2016. Rev Inst Med Trop Sao Paulo. 2019;61:e21. doi:10.1590/ S1678-9946201961021).

26. Podlekareva DN, Mocroft A, Post FA, et al. Mortality from HIV and TB coinfections is higher in Eastern Europe than in Western Europe and Argentina. AIDS. 2009;23(18):2485-2495. doi:10.1097/ QAD.0b013e3283326879)

27. Aung ZZ, Saw YM, Saw TN, et al. Survival rate and mortality risk factors among TB-HIV co-infected patients at an HIV-specialist hospital in Myanmar: A 12-year retrospective follow-up study. Int J Infect Dis. 2019;80:10-15. doi:10.1016/j.ijid.2018.12.008.

28. Abdullahi OA, Ngari MM, Sanga D, Katana G, Willetts A. Mortality during treatment for tuberculosis; a review of surveillance data in a rural county in Kenya. PLoS One. 2019;14(7):e0219191. Published 2019 Jul 11. doi:10.1371/journal.pone.0219191

29. Mabunda TE, Ramalivhana NJ, Dambisya YM. Mortality associated with tuberculosis/HIV co-infection among patients on TB treatment in the Limpopo province, South Africa. Afr Health Sci. 2014;14(4):849854. doi:10.4314/ahs.v14i4.12. 